\title{
A Contrastive Analysis of Two English Versions of HeTangYueSe from the Perspective of Reception Aesthetics

\author{
Yuanyuan Cao*
}

School of Foreign Languages, Wuhan University of Science and Technology.

1634597979@qq.com

* The corresponding author

Keywords: HeTangYueSe; Reception Aesthetics,; Comparative study; Prose Translation

\begin{abstract}
Prose is a common style among the literature. It has an extensive content and flexible structure. The major feature of prose is shape dispersing but spirit concentrating. Therefore, expressing the original artistic charm is the highest standard for prose translation.

Traditional translation emphasizes the equivalence on language and structure between the translation and the original text. Reception Aesthetics, as a new methodology, support the view that prose translation should express the original romance charm so that the reader can experience the equivalent beauty.

In the process of translation, a translator not only represent the original meaning and content but also the original emotion. Therefore, it is essential for a translator to possess a profound background knowledge and grasp the essential connotation exactly. On the basis of this fact, this paper employs an important concept in Reception Aesthetics, horizon of expectation, to demonstrate the feasibility and importance of it in prose translation. Two English versions by Yang Xianyi and Zhu Chunshen about HeTangYueSe are analyzed, and a comparison are made between the two translations on different levels in this paper. This paper tends to make a comparative study of the two English versions by Yang Xianyi and Zhu Chunshen from the perspective of Reception Aesthetics to illustrate the reproduce of beauty and provide the translators with the specific translation skills.
\end{abstract}

\section{Introduction}

HeTangYueSe was written by Zhu Ziqing in 1927 and it carried a gloomy emotion with a particular style. Therefore, it is more difficult in translation.

HeTangYueSe has been considered as one of the greatest prose in modern Chinese literate. As a kind of literary form, prose enjoys wide acceptance and great popularity. However, comparing with other literary forms, the study of prose translation has lagged far behind especially in the prospective of Reception Aesthetics.

\section{Reception Aesthetics}

With the development of the literary theory, Reception Aesthetics was raised in the 1960s. The typical representatives are Hans Robert Jauss and Wolfgang Iser. Then it happened a revolution in the field of literary criticism. It is a kind of methodology in regard to the study of the factors influlencing the reader's reception of a literary work but not a general study about literary theory.Because the essence of artistic conception lies in readers' appreciation.[1] The real-life situation,however, is unfortunately that, while the best translators largely meet these expectations, most of those who comment on (scholars, critics) and almost all who use (academics) translations largely fail to meet them.[2]

Reception Aesthetics was made up of indeterminacy, horizon of expectation, concretization and so on. Horizon of expectation and indeterminacy of text are the two key concepts explored in the paper.

According to Leech, the subject of linguistic appropriateness has not been neglected by the 
literary theorists of the past.[3] In the theory of Reception Aesthetics, a literary work has two parts: one is the work which is full of indeterminacy; the other one is the readers' concretization when they read a literary work. Only having the good combination of these two aspects, can a complete literary work be achieved.

The reader's horizon of expectations are influenced by a lot of factors, such as occupation, hobby, reading experience, education aesthetic value and so on. All these factors would have an effect on reader's reception of the original work. Newmark claimed that translation theory derives from comparative linguistics, and within linguistics, it is mainly an aspect of semantics; all questions of semantics relate to translation theory.[4]

\section{A Comparative Analysis of Two English Versions of HeTangYueSe}

There are five English versions of HeTangYueSe at present, which are from Yang Xianyi, Zhu Chunshen, Wang Shusheng, Li Ming and Howard Goldblatt respectively. This paper will choose two versions, which were translated by Yang Xianyi and Zhu Chunshen, to make a comparison with Reception Aesthetics theory on different levels .

Translation not only involves transfer of two languages, but also covers the switch of meanings. In The Theory and Practice of Translation, Nida put forward that translating is essentially a process of communication and this means that a translator must go beyond the lexical structures to consider the manner in which an intended audience is likely to understand a text, because so much depends on the underlying presuppositions of the respective source and target cultures.[5]

Phonological Reproduction. According to Liu Miqing, "Beat, a kind of goodness in sound, is also found in prose. In prose, beat is always taking the form of wave movement."[6]

Example:

The original version:

月光如流水一般, 静静地泻在这一片叶子和花上。薄薄的青雾浮起在荷塘里...

Yang Xianyi's version:

Moonlight cascaded like water over the lotus leaves and flowers, and a light blue mist floating up from the pool...

Zhu Chunshen's version:

The moon sheds her liquid light silently over the leaves and flowers, which, in the floating transparency of a bluish haze from the pond, look as if they had just been bathed in milk...

As for “静静”, Yang uses a "cascade" to show that the moonlight pours out on the leaves and flowers, which is not consistent with the author's intention. Because the author wanted to present a picture of the moonlight's serenity. In comparison, Zhu chooses an exquisite word, "silently", which has a very close equivalence to the author's intention. As for “薄薄”, Yang selects an adjective, "light", which not only expresses the original version's meaning but also keep the primary form. While Zhu uses a noun, "transparency", which means that something is clear, but the original version intends to express that the blue mist is thin. According to Tian Weining, these aesthetic features of lyric prose require translators to translate from an aesthetic perspective.[7] In other words, Zhu's version is not so accurately.

Lexical Reproduction. A translator should make efforts to present the beauty from lexical level during translation. That is to say, translation of a beautiful lyric prose should achieve aesthetic reproduction in the translation process.[8] Therefore, it is an obvious requirement for a translator to have a high level on word option and collocation.

Example:

The original version:

零星地点缀着这些白花, 有缞娜地开着的, 有羞涩地打着朵儿的...

Yang Xianyi's version:

starring these tiers of leaves were white lotus flower, alluringly open or bashfully in bud...

Zhu Chunshen's version:

Here and there, layers of leaves are dotted with white lotus blossoms... 
“点缀”, a very vivid word, means decorate by adding designs to something. In Yang's version, "star", is regarded as a verb in this sentence, which makes the target language more vivid. In Zhu's version, he chooses a passive voice, "are dotted". Although it keeps the original meaning, the form is not flexible. Consequently, Yang's horizon of expectation is much closer equivalent to the author's.

Syntactic Reproduction. Syntax, as a branch of linguistic, is about principle of forming and understanding correct English sentences. The form or structure of a sentence is governed by the rules of syntax. These rules specify word order, sentence organization, and the relationships between words, words classes and other sentence elements. A translator should make great effort to organize the target language during translation.

Example:

The original version:

我爱热闹,也爱冷静;爱群居,也爱独处。

Yang Xianyi's version:

I like both excitement and stillness.

Zhu Chunshen's version:

I like a serene and peaceful life, as much as a busy and active one; I like being in solitude, as much as in company.

Beauty is not only reflected in the aesthetic effect of the artistic conception and taste of beauty, but also in the form of rhythm, lexical, sentences, rhetorical techniques and other aspects.[9] As for the original version, the parallel structure provides a sense of balance and proportion and creates a resounding effect. However, in Yang's version, this beauty of parallel structure is not presented at all. Yang just uses a simple sentence, which can not keep the original meaning. On the contrary, Zhu's version is very trim and balanced. He employs twice "I like", and twice "as much as", which is entirely consistent with the author's intention. Therefore, Zhu's horizon of expectation is much in accordance with readers'.

\section{Summary}

At present, prose translation is more and more progressive. However, the analysis of prose translation is far more behind it, especially the systemic analysis. Reception Aesthetics, as a kind of literary criticism theory, has been hardly applied into prose translation study.

This paper demonstrates that it is of great significance to apply Reception Aesthetics to prose translation. It considers the reader's horizon of expectations. Thus the translator is a reader as well as a writer.

This paper makes a comparative study between the two English versions of HeTangYueSe from the perspective of Reception Aesthetics, drawing a conclusion that both of the two versions reproduce the aesthetic values of the original text in some aspects. Thus it is not appropriate to say that one is good or not, for every translation is a creation and presents different styles.

However, this paper only study the prose translation from the aspect of Reception Aesthetics due to the limitation of the author's ability. The application of Reception Aesthetics to prose translation is a young discipline and still a long and hard way to go.

\section{References}

[1] Z.D. Pan: Foreign Language and Their Teaching, Vol.6 (2017) No.1, p.95.

[2] R. Burton: The Art of Translating Poetry (Pennsylvania State University, London 1998).

[3] G.N. Leech: A Linguistic Guide to English Poetry (Foreign Language Teaching and Research Press, Beijing 2001).

[4] P.A. Newmark: Approaches to Translation (Shanghai Foreign Language Education Press, Shanghai 2004).

[5] E.A. Nida: The Theory and Practice of Translation (Shanghai Foreign Language Education Press, Shanghai 2004). 
[6] M.Q. Liu: Translation Aesthetic Theory (Foreign Language Teaching and Research Press, Beijing 2011).

[7] W.N. Tian: On the English Translation of Lyric Prose from the Perspective of Translation Aesthetics (Ph.D., Capital Normal University, China 2008), p.28.

[8] J.J Li: The Aesthetic Reproduction of Modern Lyric Prose in the Process of English Translation from the Perspective of Translation Aesthetics (Ph.D., Northeastern University, China 2013), p.33.

[9] H. He: Journal of Zhengzhou University of Aeronautics, Vol. 35 (2016) No.2, p.128.

[10] P.J. Zhang: Selection of Modern Chinese Prose Translated into English (Shanghai Foreign Language Education Press, Shanghai 2007). 